\title{
Overlapping tracks processed by TIG melting TiC preplaced powder on low alloy steel surfaces
}

\author{
S. Mridha ${ }^{1}$ and T.N.Baker ${ }^{2}$ \\ ${ }^{1}$ Advanced Materials and Surface Engineering Research Unit \\ Department of Manufacturing and Materials Engineering \\ Kulliyyah of Engineering, International Islamic University Malaysia \\ PO BOX 10, 50725 Kuala Lumpur, Malaysia. \\ ${ }^{2}$ Department of Mechanical and Aerospace Engineering, University of \\ Strathclyde, Glasgow, G1 1XJ
}

Email: ${ }^{1}$ shahjahanmridha@gmail.com and ${ }^{2}$ neville.baker@strath.ac.uk

\begin{abstract}
An overlapping composite track coating was produced on a steel surface by preplacing an $0.5 \mathrm{~mm}$ thick layer of $\mathrm{TiC}$ powder and then melting using a TIG torch of constant energy input. The influence of the overlapping operation on preheating of the substrate, the dissolution of $\mathrm{TiC}$ particulates and the subsequent depth and hardness of the composite layer was analysed. The melt microstructure consisted of both undissolved and partially dissolved TiC particulates, together with a variety of morphologies and sizes of $\mathrm{TiC}$ particles precipitated during solidification. Preheating, resulting from the overlapping operation occurred, producing additional melting of the TiC particulates and deeper melt depths but with a reduced volume fraction of $\mathrm{TiC}$ precipitates in the subsequent tracks. A maximum hardness of over $800 \mathrm{Hv}$ was developed in the composite layer. The high hardness was unevenly distributed in tracks melted at the initial and final stages, while it varied across the melt depths in other tracks.
\end{abstract}


Keywords: TIG melting, Coating, Steel, Titanium carbide, Overlapping, Preheating, Microstructure, Hardness

\section{INTRODUCTION:}

Metal components frequently lose functionality through wear, by a combination of modes such as abrasion, impact, or corrosion. To alleviate such damage, and thereby extend the service life, modification of surfaces is frequently undertaken. ${ }^{1,2}$ This surface engineering approach has been adopted across many industries, such as cement, mining, steel, petrochemical, power, sugar cane and food. ${ }^{3}$ Normally, the base material of the component is selected for strength and price, while the details of the surface modification are selected for specific tribological conditions to which the critical sections of the part will be subjected in service.

Many surface engineering technologies have been developed to combat surface failure in steels, but each has its own limitations. Deposition of thin hard coatings can improve tribological properties in terms of low friction and wear. However, the coatings can fail by deformation of the subsurface, if the load is high. Reinforcement of metals with ceramics can increase strength, stiffness, wear resistance and high temperature strength, and affect a decrease in weight. Although most of the work on metal matrix composites (MMC's) is centred on light metal alloys, there is considerable interest in developing iron-based MMCs for wear resistant applications. Among the common ceramic materials used as a reinforcement is titanium carbide (TiC), ${ }^{4,5}$ which compared with high density iron-based alloys $\left(7.75 \mathrm{~g} \mathrm{~cm}^{-3}\right)$, has a lower density (4.90-4.93g $\left.\mathrm{cm}^{-3}\right)$, high hardness $\left(3200 \mathrm{~kg} / \mathrm{mm}^{2}\right)$, good 
wettability and high thermal stability. The incorporation of ceramic particles into molten metal surfaces to produce MMC layers is popular because this method can tailor the surface to suite the requirements of specific applications. High power laser and electron beam melting techniques have been used extensively for processing such composite layers, which are reported to increase wear and corrosion resistance significantly. ${ }^{6-11}$ These techniques, however, have a limited application because of the expense in their establishment and the precise control of the system. ${ }^{12-15}$ An alternative, more economic and novel method was developed using conventional TIG torch melting for surface modification work. ${ }^{16-19}$ This TIG surface melting process is simpler, cheaper to establish and flexible in operation, economical in time, energy and manufacturing procedure, compared to laser and electron beam processing. Following the publication of the initial research, ${ }^{16-19}$ an increasing number of papers based on this work have been reported in the literature. ${ }^{20-35}$ However, there are few reports of investigations which produce significant relationships between the processing conditions and the coating quality, especially on steel substrates. A recent experimental study by Mridha et al ${ }^{32}$ incorporated TiC particulates into an AISI 4340 low alloy steel surface, using a powder preplacement technique and melting under a TIG torch to give a single track. Depending on the processing conditions used, 0.5-1.0 mm thick defect-free composite layers on the substrate surfaces, which had hardness values of about 2.5 to 4 times the base hardness of $300 \mathrm{Hv}$, were successfully produced. ${ }^{32}$

Previously surface engineering work using the TIG technique, ${ }^{20-35}$ produced either a small hemispherical volume of modified surface or a single melt 
track with a width of a few millimetres, running the length of the specimen. However, in many service applications there is a frequent requirement to modify a much greater surface area. This necessitates the overlapping of many melted tracks with the additional problems of preheating of the regions of the substrate where subsequent tracks are melted, as reported for laser processing. ${ }^{36-41} \mathrm{Hu}$ and Baker ${ }^{38,39}$ described 'preheat' as the heat developed from melting the initial track, which then diffused by conduction throughout the work piece. Furthermore, due to the influence of the preheat on the microstructure, characterisation of a single track will not be representative of the microstructural variations which occur between the first and the subsequent tracks, giving misleading information. The same criticism is true of the variations in the melt depth, changes in hardness with depth through the processed surface, defect morphology and track dimensions.

Some overlapping investigations have been published on titanium alloys, initially considering laser nitriding, ${ }^{37-39}$ followed by laser powder alloying with $\mathrm{SiC},{ }^{40}$ and finally a combination of laser nitriding and $\mathrm{SiC}$ powder alloying. ${ }^{41}$ The authors reported that the microstructure, hardness and melt depth were related to a specific track, and the influence of preheating from previous tracks is apparent.

The present work builds on that carried out on titanium, producing a multitrack composite layer on a steel substrate surface preplaced with TiC particulates, but using a TIG torch as the melting source. The work considers particularly, the influence of overlapping on microstructure, melt depth, hardness development, defect morphology and dissolution of the $\mathrm{TiC}$ particulates. The results are compared with available data for single track 
MMC coatings on steel surfaces. In this paper, the original TiC particles are described as particulates, while those formed from titanium and carbon atoms produced by dissolution and dissociation of the TiC particulates, with subsequently nucleation and growth during the solidification of the melt, are described as precipitates.

\section{EXPERIMENTAL}

Titanium carbide (TiC) powder of 99.5\% purity, with the nominal size of 45$100 \mu \mathrm{m}$ was used as reinforcing material on an AISI 4340 low alloy steel substrate of composition given in Table 1 . The steel plate was $100 \times 40 \times 15$ $\mathrm{mm}^{3}$ in size, ground on emery paper and degreased in acetone, before any ceramic powder was preplaced for alloying. TiC powder mixed with a PVA binder, was preplaced on the steel surface to a thickness of $\sim 0.5 \mathrm{~mm}$ and dried in an oven at $80^{\circ} \mathrm{C}$ for $1 \mathrm{~h}$ to remove the moisture.

A Miller Dynastry 300 DX TIG equipment was used to generate a torch with a $2.4 \mathrm{~mm}$ diameter thoriated tungsten electrode. The preplaced powder substrate surfaces were positioned $1 \mathrm{~mm}$ below the electrode tip, and overlapping melted tracks were produced by scanning the torch set at $80 \mathrm{~A}$ current using a speed of $1 \mathrm{~mm} \mathrm{~s}^{-1}$, along $40 \mathrm{~mm}$ track of the sample width. This was shielded using pure argon, purged at $20 \mathrm{~L} \mathrm{~min}^{-1}$, to prevent oxidation. 50\% overlaps were made under this argon environment and a total of thirteen overlapping tracks were produced on the $15 \mathrm{~mm}$ thick specimen to develop the MMC composite coating. A constant time interval of $35 \pm 5 \mathrm{~s}$ was taken between every two tracks (from the end of a track to the start of the following one). The travelling direction and distance were adjusted by a computer controlled specimen stage and the tracks were laid down starting 
from the central section of the steel plate to avoid the cooling rate associated with the plate edge influencing the microstructure. The temperatures of the specimen at two different positions, the middle of the first and the middle of the final $\left(13^{\text {th }}\right)$ overlapping tracks, were recorded during the melting operation using thermocouples which penetrated halfway through the underside of the steel substrate.

Table 1: Composition of AISI 4340 low alloy steel in wt-\%.

\begin{tabular}{ccccccccc}
\hline $\mathrm{C}$ & $\mathrm{Mn}$ & $\mathrm{Si}$ & $\mathrm{S}$ & $\mathrm{P}$ & $\mathrm{Cr}$ & $\mathrm{Ni}$ & $\mathrm{Mo}$ & $\mathrm{Fe}$ \\
\hline $0.38-0.43$ & $0.60-0.80$ & $0.15-0.30$ & 0.04 & 0.035 & $0.70-0.90$ & $1.65-2.0$ & $0.20-0.30$ & $\mathrm{Bal}$.
\end{tabular}

Metallographic samples of the overlapping track cross sections were prepared using standard techniques and were chemically etched in a 5\% Nital solution for a period of 5 s. An Olympus GX-51 optical microscope and a Hitachi SU6600 field emission scanning electron microscope 5600 were used for microstructural analysis. A Mitutoyo MVK-G1 microhardness tester was used to determine the hardness across melt thickness of the tracks at 500 gf with $10 \mathrm{~s}$ delay. The microhardness measurement was conducted on polished cross sections of all 13 tracks. Measurement was taken at the centre line of each melt pool, i.e., at the greatest depth of the hemispherical melt pool, at an interval of $0.20 \mathrm{~mm}$ from the surface to a depth of $1.2 \mathrm{~mm}$. The heat input $(H)$ for melting the tracks under the torch generated at $11 \mathrm{~V}$ with $80 \mathrm{~A}$ current $(I)$ and at $1 \mathrm{mms}^{-1}$ traversing speed $(S)$, was calculated using Equation 1, where $\eta$ is the efficiency of heat absorption, which is considered to be $48 \%$ for TiG torch melting. ${ }^{42}$ The heat input calculated for the processing conditions used in this investigation was $422 \mathrm{~J} \mathrm{~mm}^{-1}$. 


$$
H=\eta \frac{V I}{S}
$$

Equation 1

\section{RESULTS AND DISCUSSION:}

3.1 Surface Topography: The overlapped track surfaces were seen to be free from any cracks or other visible defects. The measured roughness of the individual melt track gave varying values and the average Ra value was 5.5 $\mu \mathrm{m}$. A certain degree of surface roughness is an inevitable feature when modification is conducted by any reinforement process. Laser processed SiC incorporated composite layer on a Ti-6Al-4V alloy was reported ${ }^{34}$ to have surface roughness value to about $7.5 \mu \mathrm{m}$, while nitriding by laser melting in a 40 vol-\% $\mathrm{N}$ atmosphere had roughness up to $5.1 \mu \mathrm{m}$. Rippling marks were more frequently observed in tracks processed in the later stage of present work. Ripples were also observed in previous work on both laser and TIG torch melted surfaces and were considered to be due to the fast freezing of the melt. ${ }^{2,20,43}$ The first tracks melted had rougher surfaces than those melted later. This may be related to the pre-heating effect of the overlapping tracks. The tracks melted in the later stages created a less viscous melt because of preheating which resulted in a smoother surface.

\subsection{Temperature changes due to 13 successive overlapped tracks:}

The temperature profiles, recorded at the middle of the first track and at the middle of the $13^{\text {th }}$ track are shown in Fig. 1 . It is to be noted that the recorded temperatures between the first and the final tracks were taken as the temperatures of the overlapping tracks, because thermocouples were not 
placed under each individual track. However, the readings provide information on the changes in the temperature during the overlapping operation.

The graphs in Fig. 1 indicate that for each track, the temperature increased almost linearly with successive overlapping time, and a peak value of $725^{\circ} \mathrm{C}$ was recorded for the $13^{\text {th }}$ track. The thermocouple at the first track recorded temperature rises successively at a rate of $\sim 1.5^{0} \mathrm{C} / \mathrm{s}$ up to the 3rd track and then at $1.0{ }^{0} \mathrm{C} / \mathrm{s}$ to a maximum of $400{ }^{\circ} \mathrm{C}$ at the $5^{\text {th }}$ track After that the temperature remained almost constant, with only a slight decline recorded (about $20^{\circ} \mathrm{C}$ ) with increasing number of overlapping tracks. Compared to the thermocouple at the first track, the temperatures recorded by the thermocouple at the $13^{\text {th }}$ track show a much slower but a linear increase to $400^{\circ} \mathrm{C}$, during overlapping up to the $6^{\text {th }}$ track at a rate of $\sim 0.9^{\circ} \mathrm{C} / \mathrm{s}$. Thereafter the temperature increased successively to $725^{\circ} \mathrm{C}$ at the final track, but that of the first track remained at around $400^{\circ} \mathrm{C}$. It is also to be noted from Fig. 1, that the temperature increased with time when the torch was on the specimen, until a peak value was reached as the end of the track was approached. The temperature then reduced with time ( $35 \pm 5 \mathrm{~s})$, as the specimen was repositioned before the next track was melted.

The energy input for each of the tracks can be considered constant when the melting conditions were constant. The energy transferred from the specimen to the surroundings during the time interval between melting of the tracks, depends on the length of the time interval and the temperature difference between the specimen and the surroundings. This observation suggests that preheating is significant during overlapping process. Recently, preheating 
was also reported in TIG processing a single-track coating of $50 \mathrm{~mm}$ in length. $^{44}$

3.3 Melt configuration and depth: The cross sectional view for each of the overlapped tracks produced a hemispherical shape melt pool, but the $50 \%$ overlapping used in this work resulted in an increased melt depth with successive tracks, Fig. 2.

The micrograph in Fig. 2 shows that the depth of the heat affected zone (HAZ) increased significantly in successive tracks, while the melt depth increment is not consistent, as seen in Table 2. However, with some exceptions, the melt depth in Table 2 increased with the sequence number of the overlapping tracks, i.e., preheating, as expected, developed greater melt depths. Compared to that of the first track, tracks 12 and 13 gave the maximum increase of $70 \%$ and $98 \%$ in the melt depth, respectively.

Table 2: Melt depths of 13 overlapping tracks embedded with TiC.

\begin{tabular}{ccccccccccccc}
\hline \multicolumn{10}{c}{ Track No./Average melt depth in $\mu \mathrm{m}$} \\
\hline 1 & 2 & 3 & 4 & 5 & 6 & 7 & 8 & 9 & 10 & 11 & 12 & 13 \\
\hline 1280 & 1345 & 1400 & 1355 & 1530 & 1660 & 1645 & 1635 & 1455 & 1655 & 1695 & 2430 & 2805 \\
\hline
\end{tabular}

3.4 Microhardness measurement: The measured hardness of all tracks is given in Table 3. The results show a maximum hardness of $601 \mathrm{Hv}$ for track 1 and $685 \mathrm{Hv}$ for track 2. For the tracks 3-10 this maximum hardness value is over $800 \mathrm{Hv}$; tracks 5-6 retained the maximum hardness of over $800 \mathrm{Hv}$ from surface to almost the bottom of the melt, while for the tracks $8-10$, the maximum hardness of over $800 \mathrm{Hv}$ was limited to a depth of $0.60 \mathrm{~mm}$. But for the tracks 11-13, the maximum hardness varied significantly between 
627-705 Hv. However, the lowest values below $600 \mathrm{Hv}$ but above $523 \mathrm{Hv}$, which was the minimum value, were recorded in tracks 1 and 12-13, compared to the base steel substrate hardness of $300 \mathrm{Hv}$. It is to be noted that hardness was measured within the melt depth of $1.2 \mathrm{~mm}$, while the total depth of the melt layer is more than this value, as can be seen from Table 2 . Tracks 11-13 had highest preheat temperatures (see Fig. 1) compared to those tracks melted in the initial stages. This caused more dilution, giving a lower concentration of the TiC particulates and precipitates. To some extent, this explained the low hardness development in these tracks. The high level of dissolution of TiC particulates may have reduced hardness values in the tracks processed with high preheat temperatures. The development of high hardness, and the fluctuation of the maximum hardness across the melt depth, was also observed with TiC particulates embedded in single track composite coatings on steel surfaces. The concentration variation of $\mathrm{TiC}$ particulates and/or precipitates has been reported to be responsible for the fluctuation in hardness. ${ }^{32-35}$

The detailed features of the hardness indentations at different melt depths of all the overlapping tracks were examined by SEM. It was found that the indentations of higher hardness are associated with more TiC particles on, or beneath, the surface. This has been demonstrated clearly in the micrographs of indentations at different depths of two tracks in Fig. 3. The indentations in track 6 revealed many TiC particles, Fig. 3a, reflecting a hardness over 800 Hv. At a deeper melt depth in track 2 (Fig. 3b), only two particles are revealed, coinciding with a lower hardness of $\sim 650 \mathrm{Hv}$. These TiC particles revealed below the surface in many indentations, were not otherwise visible 
in the polished cross sections. This value of $650 \mathrm{Hv}$ is significantly higher than the matrix, $\sim 300 \mathrm{Hv}$, suggesting that other sources of hardening, such as quenched-in dislocations and dispersion strengthening size $\mathrm{TiC}$ precipitates may be contributing.

Table 3: Hardness of the overlapping tracks at different melt depths.

\begin{tabular}{|c|c|c|c|c|c|c|}
\hline \multirow[t]{2}{*}{ Track No } & \multicolumn{6}{|c|}{ Microhardness at a melt depth below the surface, $\mathrm{Hv}$} \\
\hline & $0.2 \mathrm{~mm}$ & $0.4 \mathrm{~mm}$ & $0.6 \mathrm{~mm}$ & $0.8 \mathrm{~mm}$ & $1.0 \mathrm{~mm}$ & $1.2 \mathrm{~mm}$ \\
\hline 1 & 661 & 629 & 632 & 621 & 554 & 523 \\
\hline 2 & 609 & 685 & 685 & 666 & 681 & 649 \\
\hline 3 & 740 & 740 & 831 & 816 & 553 & 619 \\
\hline 4 & 940 & 831 & 734 & 777 & 807 & 797 \\
\hline 5 & 870 & 816 & 807 & 804 & 811 & 715 \\
\hline 6 & 862 & 860 & 836 & 804 & 779 & 819 \\
\hline 7 & 679 & 761 & 727 & 772 & 679 & 590 \\
\hline 8 & 768 & 809 & 670 & 700 & 705 & 685 \\
\hline 9 & 836 & 802 & 690 & 679 & 647 & 606 \\
\hline 10 & 677 & 816 & 698 & 700 & 634 & 594 \\
\hline 11 & 696 & 705 & 692 & 663 & 597 & 613 \\
\hline 12 & 547 & 547 & 594 & 571 & 627 & 602 \\
\hline 13 & 673 & 652 & 635 & 644 & 649 & 661 \\
\hline
\end{tabular}

Shaded areas showing hardness over $800 \mathrm{Hv}$

Preheating increased the temperature of the melt, which accelerated dissolution (melting point of $\mathrm{TiC}$ is $3160^{\circ} \mathrm{C}$ ) and dissociation of $\mathrm{TiC}$ particulates. 
3.5 Microstructure: The microstructures in most of the overlapping tracks contained undissolved and partially dissolved TiC particulates along with some precipitated TiC particles (track 1 in Fig. 4a). Both of these were seen more frequently in the initial tracks, and their concentration is high near to the melt-matrix interface, for example in track 2, Fig. $4 b$. Because of the energy distribution pattern of the beam, which may be Gaussian type as for a laser beam, the melt pool was hemispherical in shape, agglomeration of TiC particulates at the edges, which is commonly observed in laser processing, ${ }^{2}$ also occurred in TIG surfacing work. ${ }^{19,} 20$ The convectional flow of the melt is considered to have distributed $\mathrm{TiC}$ particulates towards the melt-matrix interface, as in tracks 1-5 seen in Fig. 4. Since the sample used was $15 \mathrm{~mm}$ thick, the heat dissipation from the liquid melt is presumed to be more from melt-matrix interface than from the top surface, and hence there was less time for dissolution of $\mathrm{TiC}$ near the melt interface. This may be the reason more partially dissolved TiC particulates occurred near to the interface. The low energy melting at the edges created a low temperature viscous melt and hence more $\mathrm{TiC}$ agglomeration occurred in these regions, Fig. $4 b$. Agglomeration of $\mathrm{TiC}$ was also found within the melt pool of tracks 4, 6, 8 and 12. These types of $\mathrm{TiC}$ distribution and segregation have also been reported in laser processed MMC coatings on titanium surfaces ${ }^{7}$ and TIG torch processed coatings on titanium and steel surfaces. ${ }^{21,27,32-35}$ TiC precipitates of globular, cubic and flower morphologies were seen in many overlapping tracks, but were not uniformly distributed in the melt microstructures. Similar morphologies of TiC precipitates were also reported in single track composite coatings. ${ }^{9,24,35}$ The TiC particulates were observed 
more frequently in the initial overlapping tracks than in the successive tracks and almost absent in the 13th track (Fig. 4c). This is believed to be related to higher TiC dissolution and increased melt volume, which occurred in the later tracks (see Table 2), due to preheating. The preheat increased diffusion of the dissolved titanium and carbon, resulting in reduced concentrations in the melt, which solidified to a structure with or without a thin distribution of TiC particles. The greater dilution and remelting of the $\mathrm{TiC}$ particles, due to overlapping effects, are probably responsible for the reduced $\mathrm{TiC}$ population in those tracks melted in the later stage of processing (Fig. 4d).

The $50 \%$ overlapping process resulted in a remelting of the TiC particulates at the edge of the proceeding track, leading to a reduction in the size of the partially dissolved $\mathrm{TiC}$ in the subsequent tracks. This is depicted in Fig. 5, where TiC particulate size was in the range 25-65 $\mu \mathrm{m}$ in track 1 (Fig. 5a) while it reduced to $20-40 \mu \mathrm{m}$ in track 13 (Fig. $5 b$ ); the micrographs were captured from areas free from $\mathrm{TiC}$ agglomeration, which were present in almost all tracks.

Pores were seen in the solidified melt pool of some tracks and more were present in the TiC agglomerated areas, Fig. $4 b$. Pores were also seen in TiC free areas in tracks 9, 10 and 12. However, the agglomeration of $\mathrm{TiC}$ was relatively low in tracks $7-13$, particularly so in track 13 . The formation of pores is thought to be related to the amount of binder added for preplacing the TiC powder before melting. ${ }^{18,19,27}$ A high fluidity melt due to preheating at the peak temperature, $725^{\circ} \mathrm{C}$ shown in Fig. 1, accelerated the evolution of the dissolved gas from the melt of track 13. This might be responsible for the creation of the much lower number of pores found in this track. High energy 
beam melting may produce higher fluidity melts, which require a longer period for solidification, giving more time to expel dissolved gases from the melt. This would result in a reduced concentration of pores in the solidified structure. The solidification time also depends on the thermal conductivity and the volume of the substrate material. However, high energy beam melting results in a higher peak temperature and a greater solubility of gases. On the other hand no cracks were seen in any of the overlapping tracks produced in this investigation.

\section{CONCLUSIONS}

This study of MMC composite coatings produced on TiC preplaced steel surfaces by overlapping tracks using a TIG torch concluded that:

1. Overlapping generated preheating and the preheat temperature increased with melting of successive tracks. The highest preheat temperature of $750^{\circ} \mathrm{C}$ was recorded in the last track.

2. All 13 overlapping tracks were free from any cracking, but pores were seen, especially in $\mathrm{TiC}$ agglomerated areas. Fewer pores were observed in tracks 9-13.

3. The preheating due to the overlapping operation influenced the individual track dimensions, microstructure, hardness, and dissolution of preplaced powder.

4. The microhardness map showed that the highest hardness of $>800 \mathrm{Hv}$, retained to a deeper melt depth, was found in tracks 4-6. For tracks 1113, the maximum hardness recorded was $<700 \mathrm{Hv}$. 
5. The micrographs of hardness indentations suggest that the concentration of $\mathrm{TiC}$ particles beneath the surface, which may not be visible in the cross section, is responsible for some hardness development.

6. Undissolved and/or partially dissolved TiC particulates are seen within the MMC structure but the concentration appears to be lower in the later tracks.

7. TiC precipitates occurred in the microstructure of all tracks, but at a reduced concentration in successive tracks because of the increased melt volume associated with high preheating temperatures.

\section{ACKNOWLEDGEMENTS}

The authors acknowledge the co-operation and assistance of Steven Black for the TIG overlapping work, James Kelly for metallographic study and microhardness measurement and Gerry Johnston for the Scanning Electron Microscopy. Professor Mridha thanks the Department of Mechanical and Aerospace Engineering, University of Strathclyde for the use of their facilities and materials for the investigation. He also acknowledges the International Islamic University Malaysia for granting him research leave to take up the visiting position, without which this investigation was not possible.

\section{REFERENCES}

[1] T. Bell, P.H. Morton, A. Bloyce: Mater. Sc. Eng. A, 1994, 184, 73-86. 
[2] A. Gualco, H.G. Svoboda, E.S. Surian, L.A. de Vedia: Mater. Des., 2010, 31(9), 4165-4173.

[3] M. Kirchgaßner, E. Badisch, F. Franek: Wear, 2008, 265, 772-777.

[4] H.C Man, Y.Q. Yang, W.B. Lee: Surf. Coat. Technol., 2004, 185, 7480.

[5] X.L. Wu, Y.S. Hong: Mater. Sc. Eng. A, 2001, 318, 15-21.

[6] J.H. Abboud, D.R.F. West: J. Mater. Sci. Lett., 1991, 10, 1149-1152.

[7] S. Mridha, T.N. Baker: J. Mater. Process. Technol., 2007, 185, 38-45.

[8] M.J. Chao, W.L. Wang, E.J. Liang, D. Ouyang: Surf. Coat. Technol., 2008, 202, 1918-1922.

[9] X.H. Wang, M. Zhang, X.M. Liu, S.Y. Qu, Z.D. Zou: Surf. Coat. Technol., 2008, 202(15), 3600-3606.

[10] H.-g.L. Kai-jin Huang, Zhou Chang-rong: Adv. Mat. Res., 2011, 179180, 757.

[11] T.N. Baker, in: H. Dong (Ed.), Surface Engineering of Light Alloys Aluminium, Magnesium and Titanium Alloys, Wood Publishing Ltd, Oxford, 2010, pp 398-443.

[12] C. Pfohl, K.T. Rie: Surf. Coat. Technol., 1999, 116-119, 911-915.

[13] X. Lifang, M. Xinxin, S. Yue: Wear, 2000, 246(1-2), 40-45.

[14] W. Liang, X.G. Zao: Scr. Mater., 2002, 44, 1049-1054.

[15] J. Oh, S. Lee: Surf. Coat. Technol., 2004, 179, 340-348.

[16] S. Atamert, H.K.D.H. Bhadeshia: Metall. Trans., 1989, 20A, 10371054.

[17] T.I. Khan, D. Fowles: Surf. Eng., 1997, 13(3), 257-259.

[18] S. Mridha, B.S. Ng: Surf. Eng., 1999, 15(3), 210-215.

[19] S. Mridha, H.S. Ong, L.S. Poh, P. Cheang: J. Mater. Process. Technol., 2001, 113, 516-620.

[20] S. Buytoz, M. Ulutan, M.M. Yildirim: Appl. Surf. Sci., 2005, 252, 1313-1323.

[21] S. Mridha: J. Mater. Process. Technol., 2005, 168, 471-477.

[22] D. Wenbin, J. Haiyan, Z. Xiaoqin, L. Dehui, Y. Shoushan: J. Alloys Compd., 2007, 429, 233-241. 
[23] X.H. Wang, S.L. Song, Z.D. Zou, S.Y. Qu: Mater. Sc. Eng. A, 2006, 441, 60-67.

[24] X.H. Wang, S.L. Song, S.Y. Qu, Z.D. Zou: Surf. Coat. Technol., 2007, 201, 5899-5905.

[25] J. Liu, J. Huang, J. Liu, G. Song: Adv. Mat. Res., 2010, 97-101, 13771380.

[26] L.M. Wang, J.B. Liu, C. Yuan: Mater. Sci. Forum, 2011, 675-677, 783-787.

[27] S. Dyuti, S. Mridha, S.K. Shaha: AJAS, 2010, 7(6), 815-822.

[28] S. Mridha, S. Dyuti: Adv. Mat. Res., 2011, 264-265, 1415-1420.

[29] S. Mridha, S. Dyuti: Adv. Mat. Res., 2011, 264-265, 1421-1426.

[30] S. Dyuti, S. Mridha, S.K. Shaha: Adv. Mat. Res., 2011, 264-265, 14271432.

[31] S. Dyuti, S. Mridha, S.K. Shaha: Adv. Mat. Res., 2011, 264-265, 14331438.

[32] S. Mridha, A.N.Md Idriss, T.N. Baker: Adv. Mat. Res., 2012, 445, 655-660.

[33] S. Mridha, A.N.Md Idriss, M.A. Maleque, Suryanto, Souad A.: IJMME, 2012, 7(1), 48-53.

[34] A.N.Md Idriss, S. Mridha: Adv. Mat. Res., 2012, 576, 467-470.

[35] S. Mridha, N.I. Taib, A.N. Md Idriss: Adv. Mat. Res., 2012, 576, 463466.

[36] K.P. Cooper, P. Slebodnick: J. Laser Appl., 1989, 1, 21-29.

[37] P.H. Morton, T. Bell, A. Weisheit, J. Kroll, B.L. Mordike, in: T.S. Sudarshan, J.F. Braza (Eds.), Surface Modification Technologies V, London, Institute of Materials, 1992, pp. 593-609.

[38] C. Hu, T.N. Baker: Mater. Process. Technol., 1998, 94, 116-122.

[39] C. Hu, T.N. Baker: Mater. Sc. Eng. A, 1999, 265, 268-275.

[40] M.S. Selamat, L.M.Watson, T.N. Baker: J Mater. Process. Technol., 2003, 142 (3), 725-737.

[41] T.N. Baker, M.S. Selamat: Mat. Sci. Technol., 2008, 24(2), 189-200.

[42] K.E. Easterling: Introduction to Physical Metallurgy of Welding, Butterworth-Heinemann, London (1992). 
[43] S. Mridha, T.N. Baker: Mater. Sci. Eng. A, 1991, 142, 115-124.

[44] P. Patel, S. Mridha and T.N. Baker: 'Influence of shielding gases on preheat produced in surface coatings incorporating $\mathrm{SiC}$ particulates into microalloy steel using TIG technique’ in press, Materials Science and Technology, DOI: 10.1179/1743284713Y.0000000481 


\section{List of Figures:}

Fig. 1: Showing temperature distributions in the tracks during overlapping process.

Fig. 2: Showing variation in depths of the melt zone and HAZ in successive tracks. (Right to left: track 1 to 13 ).

Fig. 3: Micrographs of hardness indentations from different overlapping tracks showing TiC particles.

Fig. 4: (a) Middle zone of track 1 showing undissolved, partially dissolved TiC particulates and precipitated $\mathrm{TiC},(b)$ track 2 showing more TiC concentration at the melt interface, and pores in the TiC agglomerated areas, $(c)$ track 13 showing no visible TiC particulates and $(d)$ track 5 showing smaller size partially dissolved TiC particulates.

Fig. 5: Showing larger particulate size in $(a)$ track 1 which reduced to smaller size in (b) track 12 because of preheating due to overlapping operation. 